\title{
Electrochemical Evaluation of a Recycled Copolymer Coating for Cultural Heritage Conservation Purposes
}

\author{
Marco Hernández-Escampa, ${ }^{1}$ Fausto Rodríguez-Acuña, ${ }^{2}$ \\ Franco Millán-Cruz, ${ }^{3}$ Pilar Rodríguez-Rojas, ${ }^{3}$ Miguel Hernández-Gallegos, ${ }^{1}$ \\ Alba Covelo, ${ }^{2}$ Carmina Menchaca-Campos, ${ }^{3}$ and Jorge Uruchurtu ${ }^{3}$ \\ ${ }^{1}$ Facultad de Ingeniería, Universidad Nacional Autónoma de México, Circuito Exterior s/n Ciudad Universitaria, \\ 04510 Mexico, DF, Mexico \\ ${ }^{2}$ Facultad de Química, Universidad Nacional Autónoma de Mexico, Circuito Exterior s/n Ciudad Universitaria, \\ 04510 Mexico, DF, Mexico \\ ${ }^{3}$ CIICAp, Universidad Autónoma del Estado de Morelos, Avenida Universidad 1001, Col. Chamilpa, 62209 Cuernavaca, \\ MOR, Mexico
}

Correspondence should be addressed to Fausto Rodríguez-Acuña; faustic99@yahoo.com

Received 28 March 2013; Revised 19 June 2013; Accepted 25 June 2013

Academic Editor: Enrique Vigueras Santiago

Copyright (C) 2013 Marco Hernández-Escampa et al. This is an open access article distributed under the Creative Commons Attribution License, which permits unrestricted use, distribution, and reproduction in any medium, provided the original work is properly cited.

\begin{abstract}
Acrylonitrile-butadiene-styrene (ABS) is a well-known discard product from the industry. This copolymer can be dissolved in organic solvents, and thin films can be created by immersion. Two requirements for coatings used for cultural heritage conservation purposes are transparency and reversibility, both fulfilled by ABS films. The aim of this work was to characterize the copolymer and to evaluate the electrochemical properties of ABS coatings applied to copper. Such performance was compared to that of a commercial varnish commonly used in conservation. The results indicate high protection values of the ABS film, generating a potential application for this waste material. The electrochemical techniques included electrochemical noise, impedance spectroscopy, and potentiodynamic polarization.
\end{abstract}

\section{Introduction}

Cultural heritage conservation constitutes a relevant field of research which frequently relies on material science to solve the challenges posed by the degradation of artifacts, architectural structures, and ornaments [1-5]. Historic, artistic, and archaeological items are frequently built of metals. Through the ages, copper and its alloys constitute a particular set of metals widely used in such manufactures [6]. Even when these materials tend to form protective patinas due to their interactions with the environment, such natural protective layers may fail, especially in highly polluted atmospheres [7]. Therefore, the application of coatings to both clean and patina covered metallic surfaces has proved to be useful to preserve cultural heritage [8]. Two highly desirable conditions of conservation-oriented coatings are transparency in order not to affect the aesthetical traits of the artifacts and reversibility, which refers to an easy removal process [9].

On the other hand, acrylonitrile-butadiene-styrene (ABS) waste and residues represent a well-known discard product from the automotive industry. Since law usually forbids the recycling of this material because all pieces must be brand new, considerable amounts of ABS become unused waste and a nuisance to dispose due to environmental restrictions. Therefore, research has been done trying to find usable recycling applications with added value to this and other polymer discards. Due to the finite reserve of hydrocarbon in the world, a proposal has been obtaining degradation oils from plastics, potentially useful as fuel [10]. However, such processes cannot avoid the presence 
of heteroatoms such as chlorine from poly(vinyl chloride) (PVC) or nitrogen from ABS. These heteroatoms relate to corrosion of machinery parts and participate in the formation of dangerous compounds such as cyanic products, $\mathrm{SO} x$ or NO$x$, in the combustion process $[11,12]$.

The mechanical and chemical properties of ABS have been studied demonstrating its durability, elongation to break, and impact resistance. However, thermooxidative processes can degrade this polymer due to hydrogen abstraction by oxygen [13]. Two models explain the ABS degradation: heat aging or physical aging [14-17]. It is well known that this polymer can be dissolved in organic solvents; also, thin layers become practically transparent. Therefore, an ABS coating potentially fulfills some of the major requirements for coatings used in cultural heritage conservation. Hence, a combination of adequate properties and ecological values due to waste recycling might be implied in the utilization of this coating for the stated purpose.

The aim of this work was to evaluate the protective properties of recycled ABS applied to copper surfaces, compared to the behavior of an aliphatic commonly used commercial coating, for conservation purposes. In order to achieve this goal, an experimental procedure was designed which allowed to (1) create coatings recurring to the dissolution properties of ABS in acetone and (2) simulate the degradation of the coatings in highly corrosive ambient. The techniques used included electrochemical noise, impedance spectroscopy, and potentiodynamic polarization. The obtained results constitute a potential contribution to the cultural heritage conservation field because an alternate coating for copper substrates is proposed. Copper and its alloys are found in a vast array of archaeological and historical artifacts around the world.

\section{Materials and Methods}

2.1. Coating Preparation. The ABS wastes were cut into small pieces, and afterwards 60 grams of this polymer was added to 1 liter of acetone under constant stirring for 10 minutes at room temperature. This way, the obtained solution is ready for the metal samples to be coated (ABS coating) by immersion.

2.2. Polymer Characterization. The recycled ABS was characterized in two states: in raw form and in solution as mentioned previously.

Thermal Analysis. Thermal analysis were carried out in a Perkin Elmer Thermal Analyzer TGA/DTA, from 30 to $500^{\circ} \mathrm{C}$, with a heating rate of $20^{\circ} \mathrm{C} / \mathrm{min}$, in normal atmosphere, using aluminum disposable holders. The samples were cut into small pieces and placed into the holder.

Infrared Spectroscopy. To evaluate the ABS structure, Fourier Transformed Infrared Spectroscopy (FTIR) was used. Infrared analysis is an extremely reliable and wellrecognized fingerprinting method. A Perkin Elmer Fourier Transformed Infrared Spectroscopy (FTIR) with Attenuated Total Reflectance (ATR) accessory was used.
2.3. Coating Thickness Measurements. Metallic plates were immersed, one (ABS-1), two (ABS-2), and three (ABS-3), for 30 seconds per immersion in the ABS solution. Scanning electronic microscope (SEM) LEO 1450VP was used to determine the thickness of the coatings for each case. Samples were attached with carbon sticky tape to the microscope holders and covered with a thin layer of $\mathrm{Au} / \mathrm{Pd}$ to prevent electrostatic charge accumulation. The images were observed at $15 \mathrm{kV}$ and secondary electrons emission.

2.4. Electrochemical Evaluation. Commercial copper coupons with an exposed area of $1.1 \mathrm{~cm}^{2}$ were embedded in acrylic resin. The coupons were polished with 600,800 , and 1200 emery paper. Afterwards, the metal samples were immersed in the coating solution for 30 seconds and then removed, to allow the solvent to evaporate. The samples were placed in a desiccator for 24 hours to be ready for testing.

A first group of samples was used as blank to evaluate the electrochemical properties of the base material in two different solutions. The first solution, $\mathrm{Na}_{2} \mathrm{SO}_{4} 0.1 \mathrm{M}$, is mildly aggressive while the second one, $\mathrm{Na}_{2} \mathrm{SO}_{4} 0.1 \mathrm{M}+3 \%$ weight $\mathrm{NaCl}$, presents highly corrosive properties and simulates an aggressive urban-marine atmosphere. As reference, a second group of coupons was coated with commercial aliphatic polyurethane (varnish). The application consisted of a single layer using a small brush, simulating the manual procedure frequent in conservation. These coupons were evaluated electrochemically as a function of time, for two weeks, immersed in the highly corrosive solution.

A third group of coupons was coated by immersion in the ABS solution (ABS-1, ABS-2, and ABS-3). Electrochemical evaluation in the highly aggressive solution was performed for the three ABS coatings for comparative purposes. Coupons with three immersion cycles were evaluated electrochemically as a function of time for two weeks.

All electrochemical evaluations performed in this work included electrochemical noise measurement, impedance spectroscopy, and potentiodynamic polarization. All measurements reported were made using a three-electrode arrangement, and potentials were quoted versus silver/silver chloride reference electrode. Electrochemical values are all corrected for the area of the working electrode.

2.4.1. Electrochemical Noise Measurement. The experimental setup used for electrochemical noise data recording consists of a working electrode, the tip of a platinum wire, and the reference electrode. The potential and current electrochemical noise oscillations were obtained simultaneously at a sampling rate of 1 point per second for 2048 seconds in each test, using an auto-ZRA ACM instrument connected to a personal computer. Removal of the DC trend from the raw noise data was the first step in the noise analysis. To accomplish this, a least squares fitting was used. The DC trend had to be eliminated because this could originate large distortions in subsequent statistical noise data processing [18].

The noise resistance $\left(R_{\text {noise }}\right)$ was obtained by statistical analysis of voltage and current noise records as follows:

$$
R_{\text {noise }}=\frac{\sigma[V(\Delta t)]}{\sigma[i(\Delta t)]},
$$




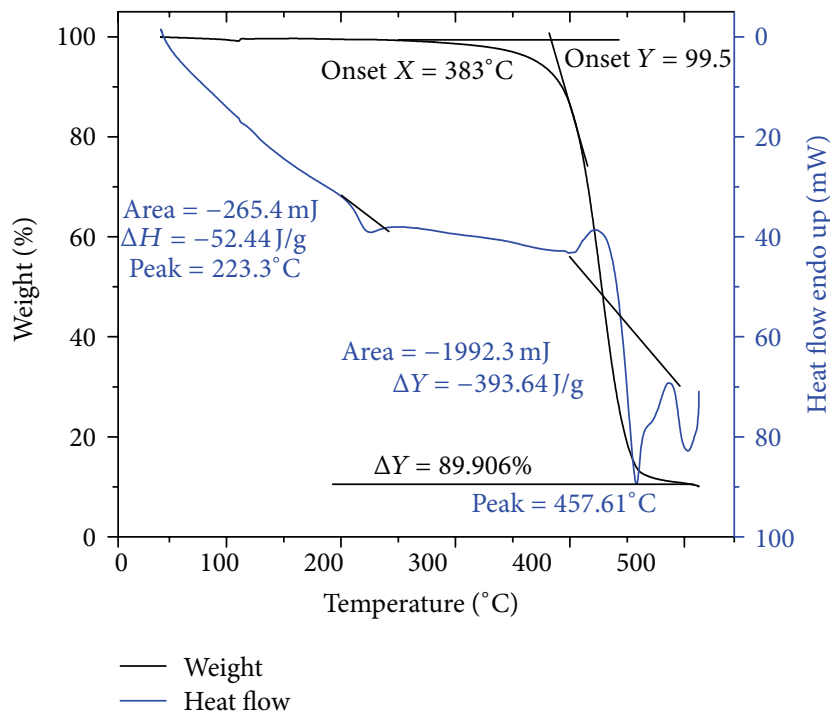

(a)

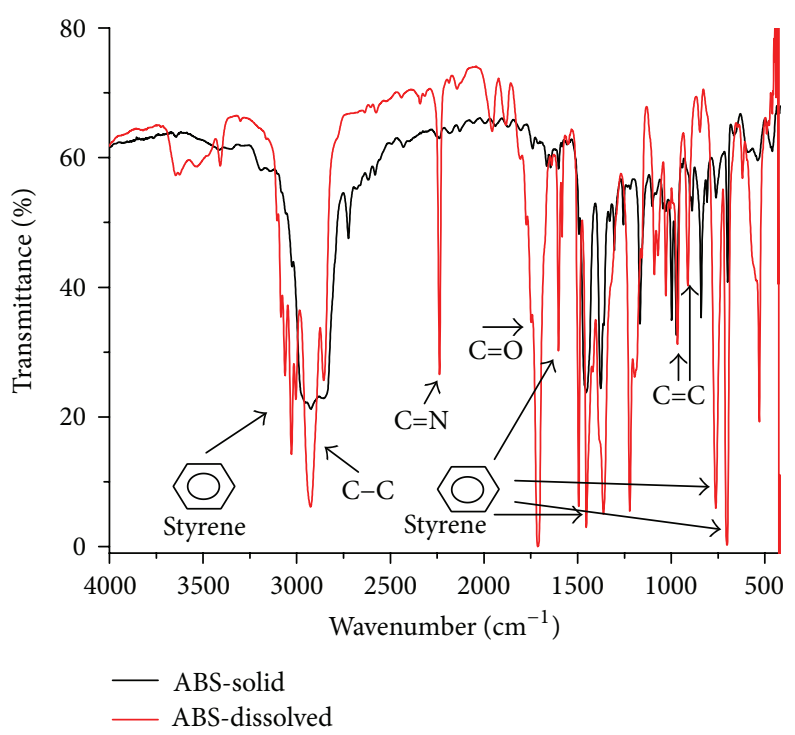

(b)

FIGURE 1: ABS characterization: (a) thermal analysis and (b) infrared spectroscopy.

where $\sigma[V(\Delta t)]$ is the standard deviation of voltage noise in time interval $\Delta t$ and $\sigma[i(\Delta t)]$ is the standard deviation of current noise in the same time interval $\Delta t$. The noise resistance was presented and obtained as a function of time. These measurements were performed to evaluate the protective properties of the coupons polymeric coating and its evolution in time.

2.4.2. Electrochemical Impedance Spectroscopy. The electrochemical impedance spectroscopy (EIS) used a sine wave. Classical three-electrode arrangement experimental set-up was used for EIS tests. The electrochemical signals were monitored by AC Gill potentiostat connected to a personal computer. The equipment was previously calibrated in accordance with the standard [19]. An alternating current (AC) signal, with a $10 \mathrm{mV}$ amplitude signal, was applied in the frequency range of $100 \mathrm{mHz}$ to $10 \mathrm{kHz}$. A silver/silver chloride electrode connected through a lugging probe was used as a reference electrode and graphite as counter electrode. These measurements were performed in the described times to evaluate different protective measurements and their evolution in time.

2.4.3. Potentiodynamic Polarization. Electrochemical polarization curve measurements were made with a scan rate of $60 \mathrm{mV} / \mathrm{min}$. Coupons were immersed in the unstirred solutions. The stabilization period before polarization was 10 minutes. The cathodic branch was performed $-1000 \mathrm{mV}$ from the rest potential and the anodic branch went up to $2000 \mathrm{mV}$ from that same rest potential.

\section{Results and Discussion}

3.1. Polymer Characterization. Figure 1(a) shows the TGA/ DTA measurement results for recycling ABS, as it is discarded. The TG curve shows one stage weight decrease between 300 and $500^{\circ} \mathrm{C}$, due to thermal decomposition with the onset in $400^{\circ} \mathrm{C}$, remaining just $10 \%$ at $500^{\circ} \mathrm{C}$, which corresponds to additives, fillers, and other aggregates present in the copolymer because of the application for which it was tailored. At the same time, the DT curve shows two main peaks, a small one around $220^{\circ} \mathrm{C}$ due to melting of the elastic butadiene and a bigger one that initiates at $420^{\circ} \mathrm{C}$ corresponding to the ABS decomposition.

The IR spectra of ABS in raw and in solution are shown in Figure 1(b). Both present characteristic peaks of the three main components, but in solution they are clearly seen: the nitrile band of acrylonitrile at $2237 \mathrm{~cm}^{-1}$, the aromatic ring of styrene at 1602, 1494,761, and $699 \mathrm{~cm}^{-1}$ [20-22], and the double bond of butadiene at $967 \mathrm{~cm}^{-1}$ trans and $911 \mathrm{~cm}^{-1}$ vinyl. The rest of nonidentified peaks in the spectra correspond to acetone major absorptions.

3.2. Coating Thickness Measurements. Figure 2(a) presents the coating thickness after one immersion with an interval between 14 and $22 \mu \mathrm{m}$, looking not very compact and disbonded. After the first immersion, the procedure was repeated twice for $30 \mathrm{~s}$ (Figures 2(b) and 2(c)). The coating looks compact but maintains a thickness around 13 to $16 \mu \mathrm{m}$. These results suggest that immersion cycles did not increase the coating thickness, but rather pores present after the first immersion are sealed and the compactness was improved (see Figure 2). Also during the second and third immersions, the ABS solution promotes partial removal of the top of the coating due to the action of the solvent.

3.3. Electrochemical Evaluation. Figure 3 shows the polarization curves of the copper coupons used as blank in $\mathrm{Na}_{2} \mathrm{SO}_{4}$ $0.1 \mathrm{M}$ and $\mathrm{Na}_{2} \mathrm{SO}_{4} 0.1 \mathrm{M}+3 \%$ weight $\mathrm{NaCl}$ solutions. It also includes the curve corresponding to the varnish coated coupons in the aggressive solution. The corrosion rates of 


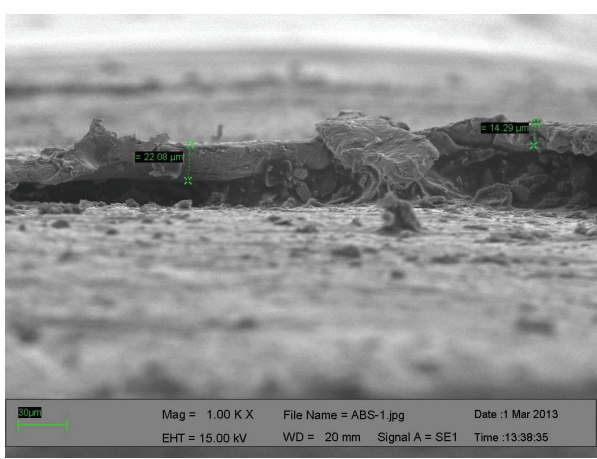

(a)

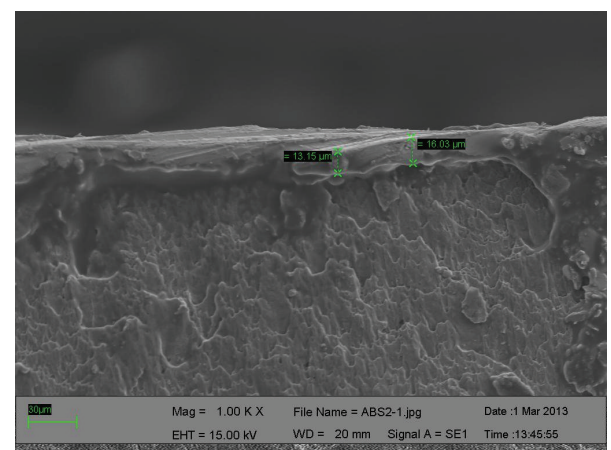

(b)



(c)

FIgure 2: Coating thickness measurement by SEM: (a) ABS-1, (b) ABS-2, and (c) ABS-3.

copper increase two orders of magnitude in comparison to the mild solution. In contrast, the copper coated with varnish decreases the corrosion rates as much as three orders of magnitude compared to the uncoated copper in the aggressive solution, demonstrating the protectiveness of the coating. The performance of the varnish was considered as reference to compare the protectiveness of the polymer coating under evaluation.

Figure 4 shows the polarization curves of the varnish coated coupons in aggressive solution for different times of immersion (0 hours up to two weeks). As time elapses, the corrosion rates increase suggesting the degradation of the coating. This is coherent with the presence of passivation zones after 24 to 48 hours due to the oxidation of the base material as the solution reaches it through the coating pores or cracks.

Figure 5 presents the electrochemical noise and impedance measurements for the varnish coated copper coupons. The Bode impedance diagrams show that the total impedance values decrease in time, although there is an increment after two weeks which once again can be related to the corrosion products formed as the coating deteriorates. Such oxidation can start as early as 24 to 48 hours according to the polarization curves. The electrochemical noise resistance values show similar behavior to the impedance measurements, although an increase can be seen since week one. Therefore, the results of the three electrochemical

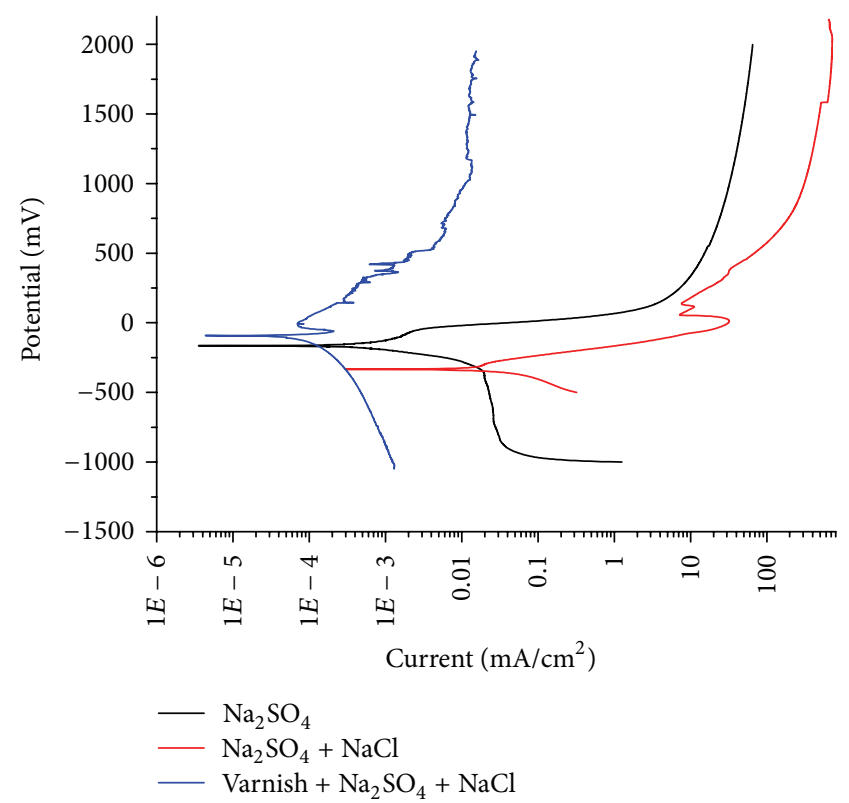

FIGURE 3: Polarization curves of blanks. Copper in $\mathrm{Na}_{2} \mathrm{SO}_{4}$ solution, copper in $\mathrm{Na}_{2} \mathrm{SO}_{4}+3 \mathrm{wt} \% \mathrm{NaCl}$ solution, copper coated with varnish in $\mathrm{Na}_{2} \mathrm{SO}_{4}+3 \mathrm{wt} \% \mathrm{NaCl}$ solution.

techniques are coherent to each other since they show similar trends. 
TABLE 1: Values of the equivalent circuits for the ABS-3 copper coupons in $\mathrm{Na}_{2} \mathrm{SO}_{4}+3 \mathrm{wt} \% \mathrm{NaCl}$ solution in time.

\begin{tabular}{|c|c|c|c|c|c|c|c|}
\hline ABS-3 & Rsol. $\left(\mathrm{ohm} \mathrm{cm} \mathrm{cm}^{2}\right)$ & Rpo $\left(\mathrm{ohm} \mathrm{cm}{ }^{2}\right)$ & $\mathrm{Cc}(\mathrm{F})$ & Dep angle & Rcor $\left(\mathrm{ohm} \mathrm{cm} \mathrm{cm}^{2}\right)$ & Ccor $(\mathrm{F})$ & Dep angle \\
\hline $0 \mathrm{~h}$ & 52 & $6.32 E 5$ & $1.13 E-9$ & 11.89 & $1.13 E 6$ & $1.32 E-6$ & 64.78 \\
\hline $24 \mathrm{~h}$ & 50 & $1.41 E 5$ & $1.65 E-8$ & 40.86 & $2.60 E 5$ & $1.60 E-5$ & 71.51 \\
\hline $48 \mathrm{~h}$ & 53 & $1.48 E 4$ & $8.53 E-5$ & 29.73 & $2.21 E 4$ & $9.60 E-5$ & 32.27 \\
\hline $1 \mathrm{w}$ & 51 & $2.23 E 3$ & $2.92 E-9$ & 7.03 & $6.42 E 3$ & $2.60 E-5$ & 41.74 \\
\hline $2 \mathrm{w}$ & 50 & $2.03 E 4$ & $9.29 E-5$ & 48.81 & $2.61 E 4$ & $1.25 E-4$ & 38.47 \\
\hline
\end{tabular}

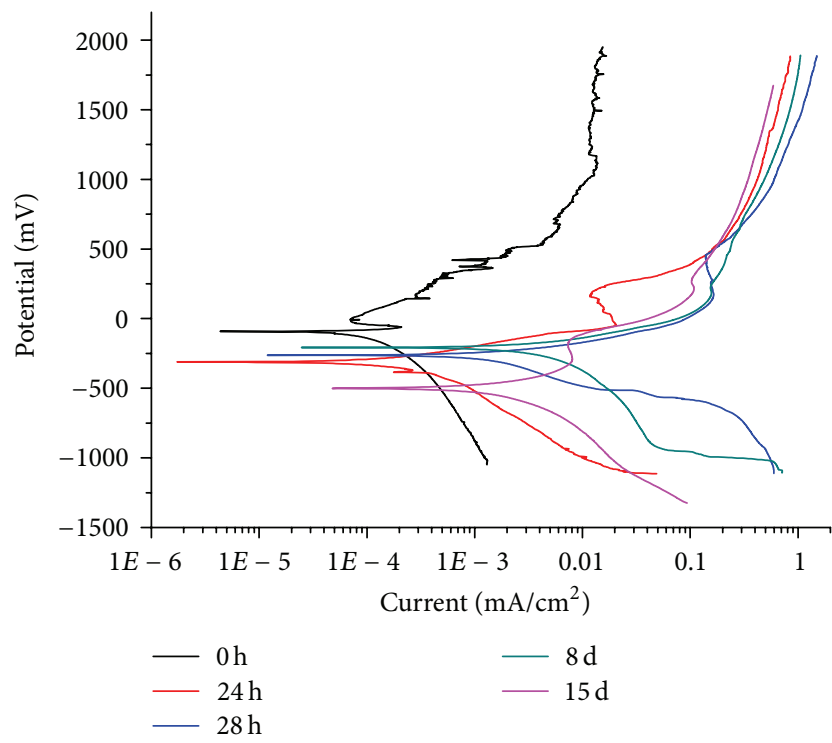

Figure 4: Polarization curves of copper coated with varnish in $\mathrm{Na}_{2} \mathrm{SO}_{4}+\mathrm{NaCl}$ solution, as a function of time.

Figure 6 shows the Bode diagrams for each of the three cases: ABS-1, ABS-2, and ABS-3. Even when no significant increase of thickness was achieved with the consecutive immersions, the total impedance increased as a function of the number of immersion. This can be related to the fact that each immersion sealed the pores of the polymer layer. The total impedance values of the ABS-3 coupons reached similar values compared to the varnish coated coupons.

Figure 7 shows the polarization curves of the ABS-3 copper coupons. In the initial time there is well-defined passivation zone suggesting corrosion processes in the surface of the base material. As time elapses, the passivation zones tend to diminish and the corrosion rates increase as the coating deteriorates. Corrosion potentials become more negative in time indicating surface activation of the metal.

Figure 8 presents the impedance and electrochemical noise measurements in time for the ABS-3 copper coupons. The Bode impedance diagrams show that the total impedance values decrease in time without any increment as observed in the case of the varnish. The electrochemical noise resistance values also show a general decrease, compared with the initial time of immersion. However, there is an increase in noise resistance values after one week. This behavior is similar to the one observed for the varnish.

Figure 9 shows the equivalent electric circuit for the corrosion process in the evaluated system. The values of the corresponding elements of the circuit are presented in Table 1. The electrochemical impedance simulation results obtained and presented reflect the coating degradation process occurring in the electrolyte as a function of time of immersion.

Figure 10 compares the total impedance $\left(Z_{t}\right)$ and noise resistance $\left(R_{n}\right)$ values in time for both the varnish and ABS3 copper coupons. In both cases, the behavior decreases as time goes by and the coatings deteriorate. The resulting values are very similar in magnitude compared to each other, and hence it is possible to suggest that the protective performance of the coatings is comparable. In the case of $Z_{t}$, the ABS coating stays with higher protective values during a considerable time. $R_{n}$ values indicate a similar behavior, even when initially, the protection of the ABS coating is slightly below in relation to the performance of the varnish. At some point in time, the parameter values are inverted and both coatings reach very similar values. With the noise resistance being independent of the frequency, the values obtained and presented in the noise impedance spectra are related totally to the coating performance [23].

Figure 11 compares the macroscopic aspect of coupons coated with varnish and ABS-3 after two weeks in the aggressive solution. The coupon protected with varnish shows blue-green corrosion products while the one coated with ABS-3 stayed in the copper color range. This suggests that the pores and/or failures in the varnish allow diffusion of bigger ions in solution such as sulfates reaching the metallic surface, which combined with chloride and oxygen may form $\mathrm{CuSO}_{4}$, as compared to those in the ABS coating. In the latter, probably smaller pores allow diffusion only of oxygen, generating a highly adherent and protective copper oxide $\left(\mathrm{Cu}_{2} \mathrm{O}\right.$ and $\left.\mathrm{CuO}\right)$ patina whose properties combine with those of the ABS-3 coating. Also, the difference observed in both samples corroborates the suggestion made as to the immersion cycles and pore sealing presented and discussed in Figure 2.

Atmospheric corrosion of copper reaction is [24]

$$
4 \mathrm{Cu}+\mathrm{O}_{2}+\mathrm{H}_{2} \mathrm{O} \Longrightarrow 2 \mathrm{Cu}_{2} \mathrm{O}+\mathrm{OH}+\mathrm{H}_{2}
$$




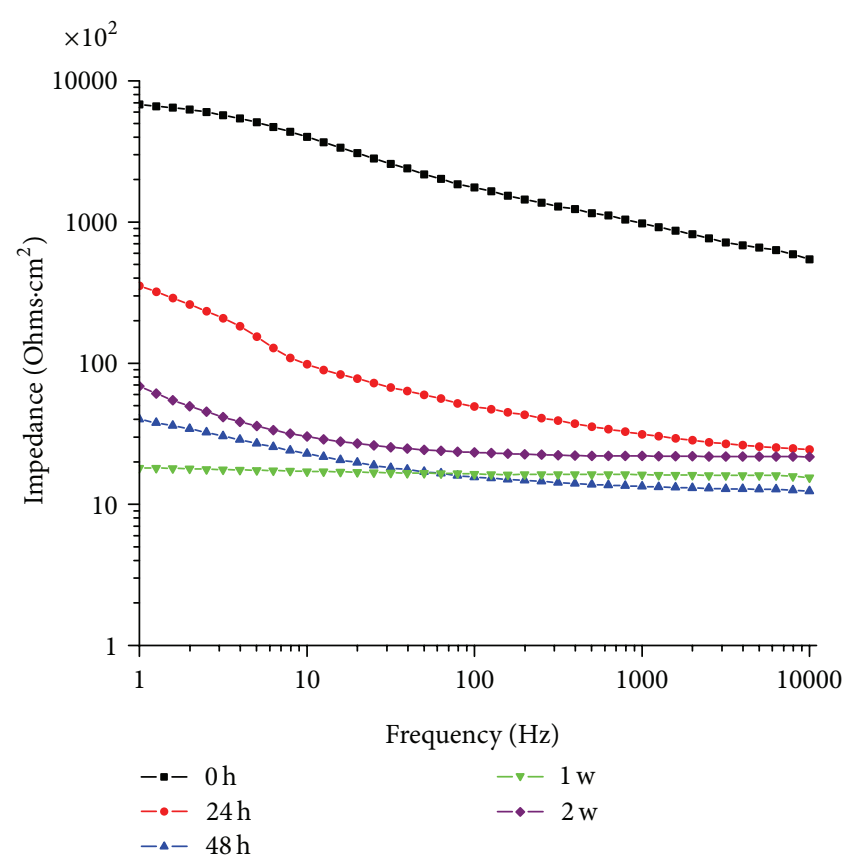

(a)

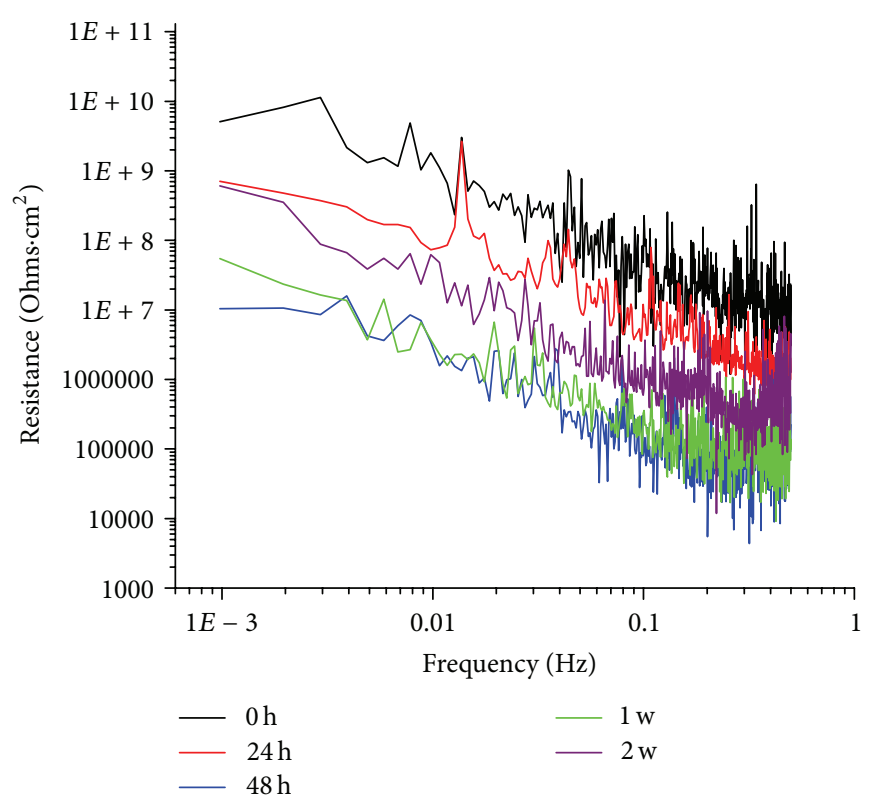

(b)

Figure 5: Copper coated with varnish in $\mathrm{Na}_{2} \mathrm{SO}_{4}+3 \mathrm{wt} \% \mathrm{NaCl}$ solution in time: (a) Bode impedance diagrams and (b) electrochemical resistance noise.

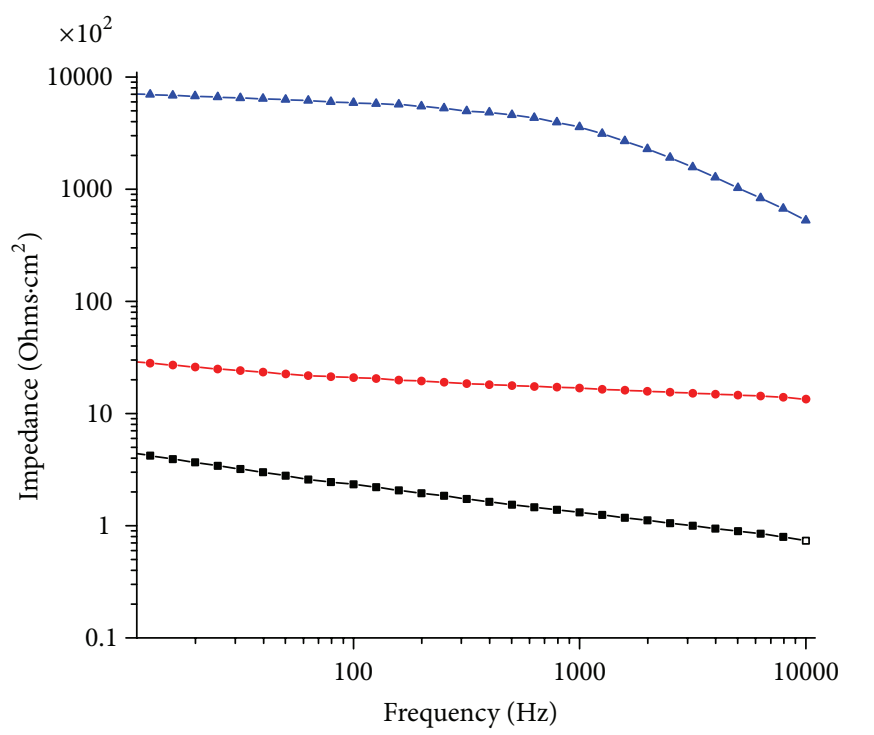

-- ABS-1
$-\bullet-$ ABS-2
--- ABS-3

FIGURE 6: Bode impedance diagrams of ABS-3 copper coated in $\mathrm{Na}_{2} \mathrm{SO}_{4}+3$ wt $\% \mathrm{NaCl}$ solution.

under polluted conditions

$$
\begin{gathered}
\mathrm{Cu}_{2} \mathrm{O}+0.5 \mathrm{SO}_{2}+1.5 \mathrm{H}_{2} \mathrm{O}+0.75 \mathrm{O}_{2} \\
\Longrightarrow 2 \mathrm{Cu}(\mathrm{OH})_{1.5}\left(\mathrm{SO}_{4}\right)_{0.25} \\
\mathrm{Cu}_{2} \mathrm{O}+\mathrm{Cl}+1.5 \mathrm{H}_{2} \mathrm{O}+0.25 \mathrm{O}_{2} \Longrightarrow 2 \mathrm{Cu}(\mathrm{OH})_{1.5} \mathrm{Cl}_{0.5}
\end{gathered}
$$

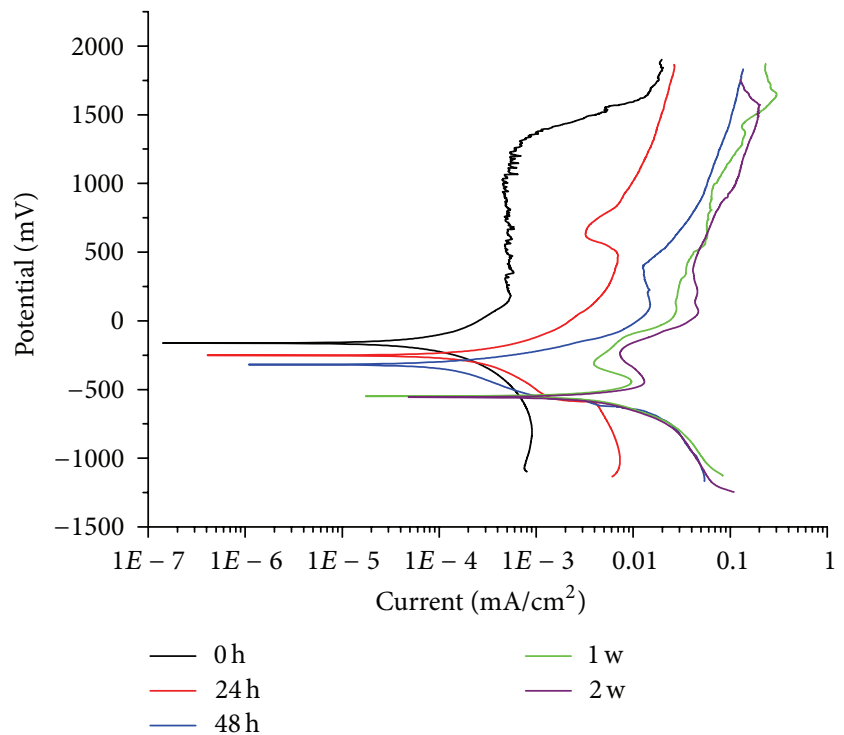

FIGURE 7: Polarization curves of ABS-3 copper coupon in $\mathrm{Na}_{2} \mathrm{SO}_{4}+$ $3 \mathrm{wt} \% \mathrm{NaCl}$ solution in time.

Corrosion of copper and its alloys forms complex patinas over the surface, being more or less protective depending upon the environmental conditions and the nature of the pollutants present. In the atmosphere the range of corrosion rates is in the order of less than $0.1 \mu \mathrm{m} /$ year for rural atmospheres up to approximately $5.6 \mu \mathrm{m} /$ year for industrialmarine environments $[24,25]$. Electrochemical measurements immersed in neutral solution on samples with patinas formed after long exposures under different atmospheres 


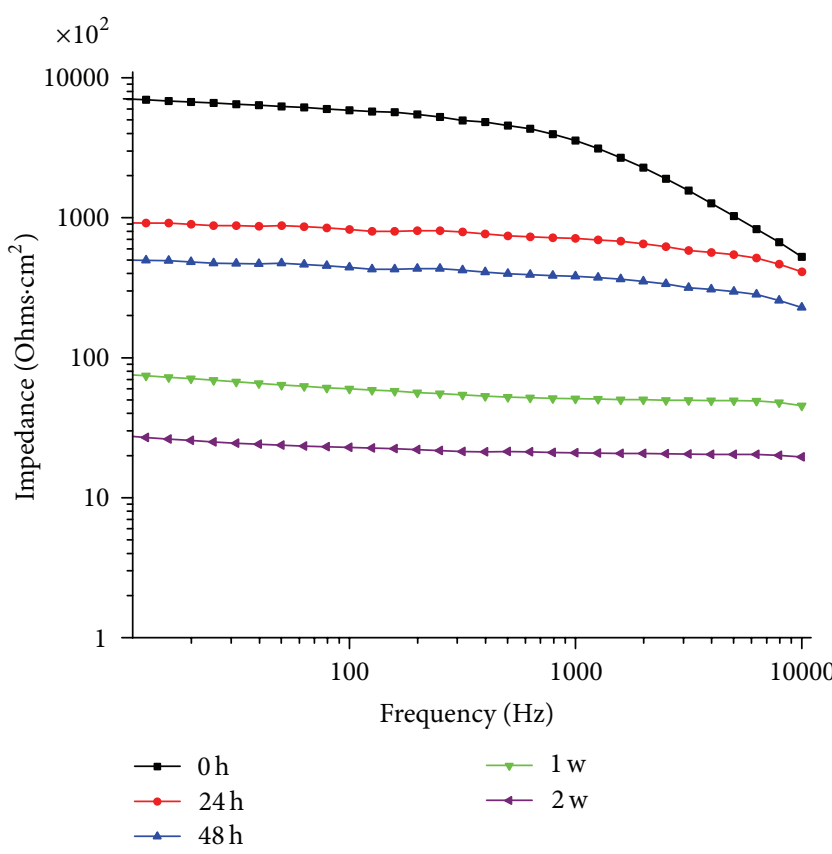

(a)

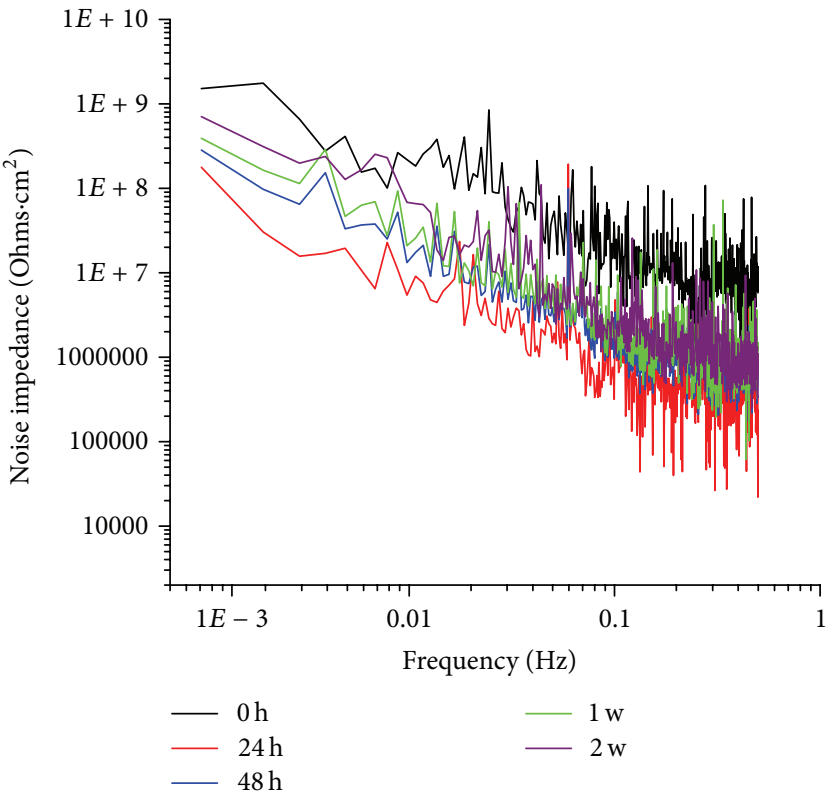

(b)

Figure 8: ABS-3 copper coupons in $\mathrm{Na}_{2} \mathrm{SO}_{4}+3 \mathrm{wt} \% \mathrm{NaCl}$ solution in time: (a) Bode impedance diagrams and, (b) electrochemical resistance noise.

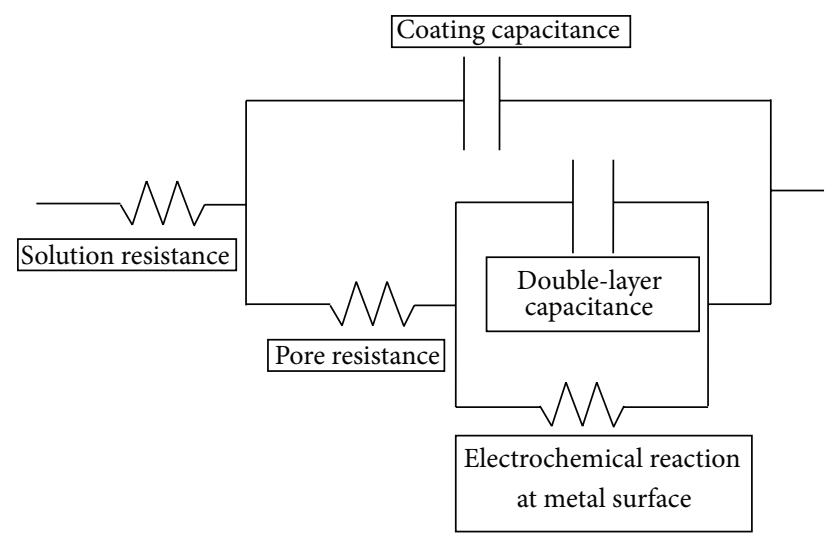

FIGURE 9: Equivalent circuit for the ABS-3 copper coupons in $\mathrm{Na}_{2} \mathrm{SO}_{4}+3 \mathrm{wt} \% \mathrm{NaCl}$ solution obtained by the electrochemical impedance technique.

rendered polarization resistance values of $5.4 \mathrm{kohms}-\mathrm{cm}^{2}$ for rural atmospheres up to $35.2 \mathrm{kohms}-\mathrm{cm}^{2}$ for industrialmarine polluted atmospheres. For comparison, bare copper presents polarization resistance values in the range of 1.5 to 6 kohms- $\mathrm{cm}^{2}$ [24].

In comparison under similar experimental conditions, for copper samples coated with a commercial alkyd varnish used for restoration and conservation of pieces of works of art of cultural and historic heritage, polarization resistance values obtained were 10 to $100 \mathrm{kohms}-\mathrm{cm}^{2}$ [25]. Results obtained

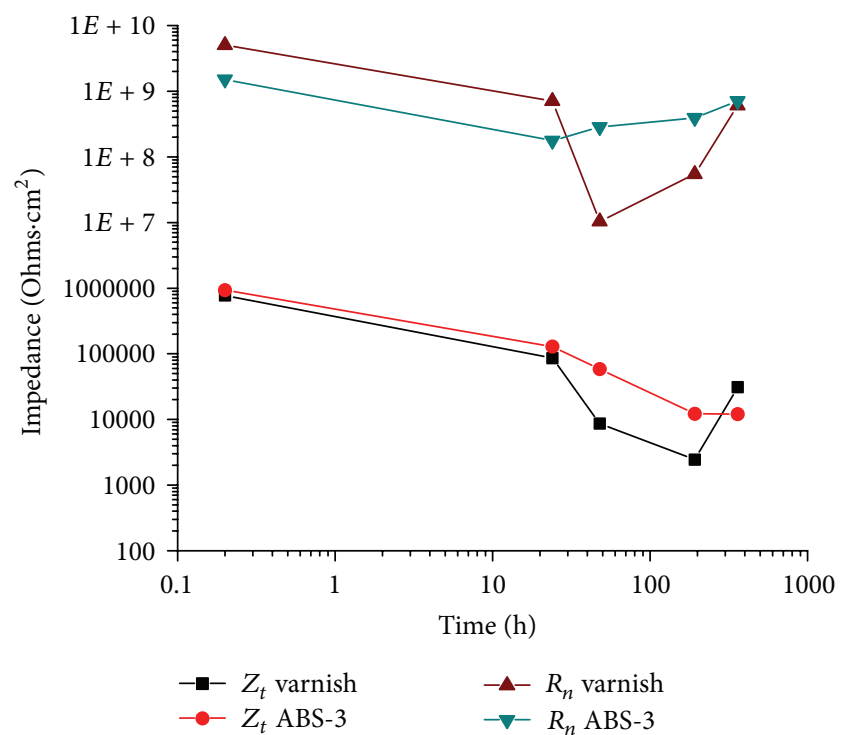

Figure 10: Comparative curves of $Z_{t}$ and $R_{n}$ in time for varnish and polymer ABS coatings as a function of time.

and presented in this work compare favorably with the results previously reported for this type of coatings. When using a copper corrosion inhibitor such as benzotriazole forming a polymeric oxide and reported [26], the polarization resistance values obtained for chloride solution were around $50 \mathrm{kohms}-\mathrm{cm}^{2}$. According to the results obtained 


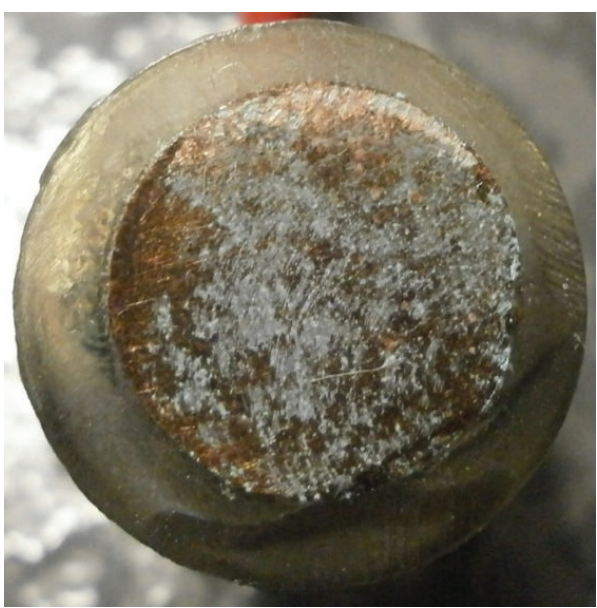

(a)

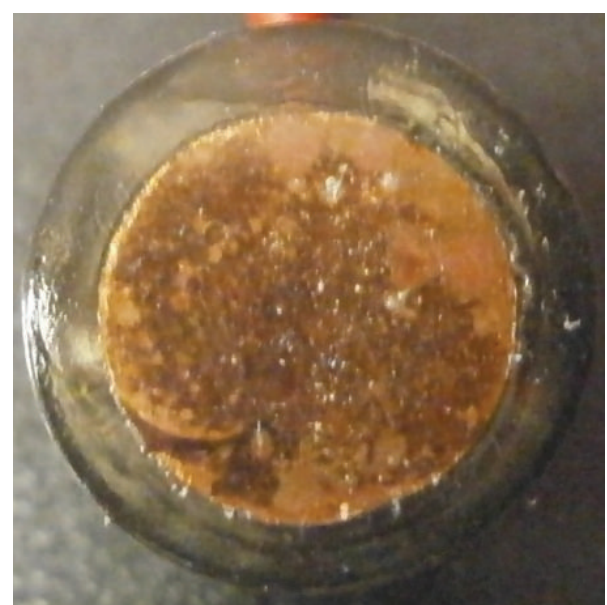

(b)

FIGURE 11: Macroscopic aspect of coupons coated after two weeks in the aggressive solution: (a) varnish and (b) ABS-3.

in this work, this coating presents good performance when compared to other corrosion protection systems $[27,28]$.

\section{Conclusions}

The ABS films fulfill two major requirements for cultural heritage conservation purposes. Both transparency and reversibility, by dissolution in organic solvents such as acetone, combine with a highly acceptable protective capacity of the material. Furthermore, the film can be easily applied, even in field conditions providing adequate temporal or long-term protection to copper artifacts, as required. This proposed application for conservation adds value to an industrial waste and contributes to finding recycling alternatives for this discard polymer, hence collaborating not only with the conservation science, but also with the ecological concerns and needs. The results indicate high performance of the coating; however, further studies are needed to characterize and optimize the system.

\section{Acknowledgments}

The authors wish to thank the Ministry of Education (SEPPROMEP) for the support provided both to the Academic Body "Desarrollo y Análisis de Materiales Avanzados" (UAEMOR-CA-43) and to the Academic Network "Diseño Nanoscópico y Textural de Materiales Avanzados." The authors are grateful to Dr. Miguel Ángel García-Sánchez (UAM-I) and Dr. René Guardían-Tapia (UAEM-CIICAp) for their timely and professional assessment at different stages of this investigation. Finally, the authors thank CONACyT for the grants received during this work.

\section{References}

[1] G. Torraca, Porous Building Materials: Materials Science for Architectural Conservation, Iccrom, Rome, Italy, 1982.

[2] G. W. Scherer, R. Flatt, and G. Wheeler, "Materials science research for the conservation of sculpture and monuments," MRS Bulletin, vol. 26, no. 1, pp. 44-50, 2001.

[3] F. Rodríguez-Acuña, J. Genescá, and J. Uruchurtu, "Electrochemical evaluation of patinas formed on nineteenth century bronze bells," Journal of Applied Electrochemistry, vol. 40, no. 2, pp. 311-320, 2010.

[4] M. Hernandez-Escampa, J. Gonzalez, and J. UruchurtuChavarin, "Electrochemical assessment of the restoration and conservation of a heavily corroded archaeological iron artifact," Journal of Applied Electrochemistry, vol. 40, no. 2, pp. 345-356, 2010.

[5] J. A. M. Salgado, J. U. Chavarín, and D. M. Cruz, "Observation of copper corrosion oxide products reduction in metallic samples by means of digital image correlation," International Journal of Electrochemical Science, vol. 7, no. 2, pp. 1107-1117, 2012.

[6] H. H. Coghlan, E. Voce, and T. K. Penniman, "Notes on the prehistoric metallurgy of copper and bronze in the Old World," Occasional Papers on Technology, no. 4, pp. 1-131, 1951.

[7] C. Chiavari, K. Rahmouni, H. Takenouti, S. Joiret, P. Vermaut, and L. Robbiola, "Composition and electrochemical properties of natural patinas of outdoor bronze monuments," Electrochimica Acta, vol. 52, no. 27, pp. 7760-7769, 2007.

[8] M. Pilz and H. Römich, "Sol-gel derived coatings for outdoor bronze conservation," Journal of Sol-Gel Science and Technology, vol. 8, no. 1-3, pp. 1071-1075, 1997.

[9] B. Appelbaum, "Criteria for treatment: reversibility," Journal of the American Institute for Conservation, vol. 26, no. 2, pp. 65-73, 1987.

[10] Y. Sakata, A. Uddin, A. Muto et al., "Thermal and catalytic degradation of municipal waste plastics into fuel oil," Polymer Recycling, vol. 2, no. 4, pp. 309-315, 1996.

[11] S. Ozdogan, S. Uygur, and N. Egrican, "Formation and dispersion of toxic combustion byproducts from small-scale combustion systems," Energy, vol. 22, no. 7, pp. 681-692, 1997. 
[12] F. Radtke, R. Köppel, and A. Baiker, "Formation of undesired by-products in deNO $_{x}$ catalysis by hydrocarbons," Catalysis Today, vol. 26, no. 2, pp. 159-167, 1995.

[13] M. D. Wolkowicz and S. K. Gaggar, "Effect of thermal aging on impact strength acrylonitrile-butadiene-styrene (ABS) terpolymer," Polymer Engineering and Science, vol. 21, no. 9, pp. 571-575, 1981.

[14] B. D. Gesner, "Environmental surface effects on ABS resins," Journal of Applied Polymer Science, vol. 9, no. 11, Article ID 10.1002/app.1965.070091117, pp. 3701-3706, 1965.

[15] J. Shimada and K. Kabuki, "The mechanism of oxidative degradation of ABS resin. Part II: the mechanism of photooxidative degradation," Journal of Applied Polymer Science, vol. 12, no. 4, pp. 671-682, 1968.

[16] M. G. Wyzgoski, "Effects of oven aging on ABS, poly (acrylonitrile-butadiene-styrene)," Polymer Engineering and Science, vol. 16, no. 4, pp. 265-269, 1976.

[17] S. R. Salman and N. D. Al-Shama'a, "Effect of thermal aging on the optical properties of ABS plastics," Polymer-Plastics Technology and Engineering, vol. 30, no. 4, pp. 343-349, 1991.

[18] J. Uruchurtu-Chavarin and J. M. Malo, "Electrochemical noise as a powerful electrochemical technique for corrosion studies," Trends in Corrosion Research, vol. 2, pp. 49-58, 1997.

[19] "Standard practice for verification of algorithm and equipment for electrochemical impedance measurements," ASTM G 10689, 2004.

[20] http://jp.fujitsu.com/group/fql/en/services/analysis/method/ftir/.

[21] R. Krache and I. Debbah, "Some mechanical and thermal properties of PC/ABS blends," Materials Sciences and Applications, vol. 2, pp. 404-410, 2011.

[22] G. Reena, S. Sangita, and K. Verinder, "Ft-ir studies of e-plastic obtained from obsolete computers," Journal of Chemical and Pharmaceutical Research, vol. 3, no. 5, pp. 660-667, 2011.

[23] M. Hernández, J. Genescá, J. Uruchurtu, and A. Barba, “Correlation between electrochemical impedance and noise measurements of waterborne coatings," Corrosion Science, vol. 51, no. 3, pp. 499-510, 2009.

[24] M. Morcillo, M. E. M. Almeida, B. M. Rosales, M. Marrocos, and J. Uruchurtu, Corrosión y Protección de Metales en las Atmósferas de Iberoamérica, CYTED, Madrid, Spain, 1999.

[25] L. Mariaca-Rodríguez, J. Genesca-Llongueras, J. UruchurtuChavarin, and L. S. Hernández, Corrosividad Atmosférica (MICAT-México), Plaza y Valdes, México, Mexico, 1999.

[26] C. Menchaca, I. Castañeda, A. Soto-Quintero et al., "Characterization of a "smart" hybrid varnish electrospun nylon benzotriazole copper corrosion protection coating," International Journal of Corrosion, vol. 2012, Article ID 925958, 10 pages, 2012.

[27] T. Kosec, D. K. Merl, and I. Milošev, "Impedance and XPS study of benzotriazole films formed on copper, copper-zinc alloys and zinc in chloride solution," Corrosion Science, vol. 50, no. 7, pp. 1987-1997, 2008.

[28] M. Finšgar and I. Milošev, "Inhibition of copper corrosion by 1,2,3-benzotriazole: a review," Corrosion Science, vol. 52, no. 9, pp. 2737-2749, 2010. 

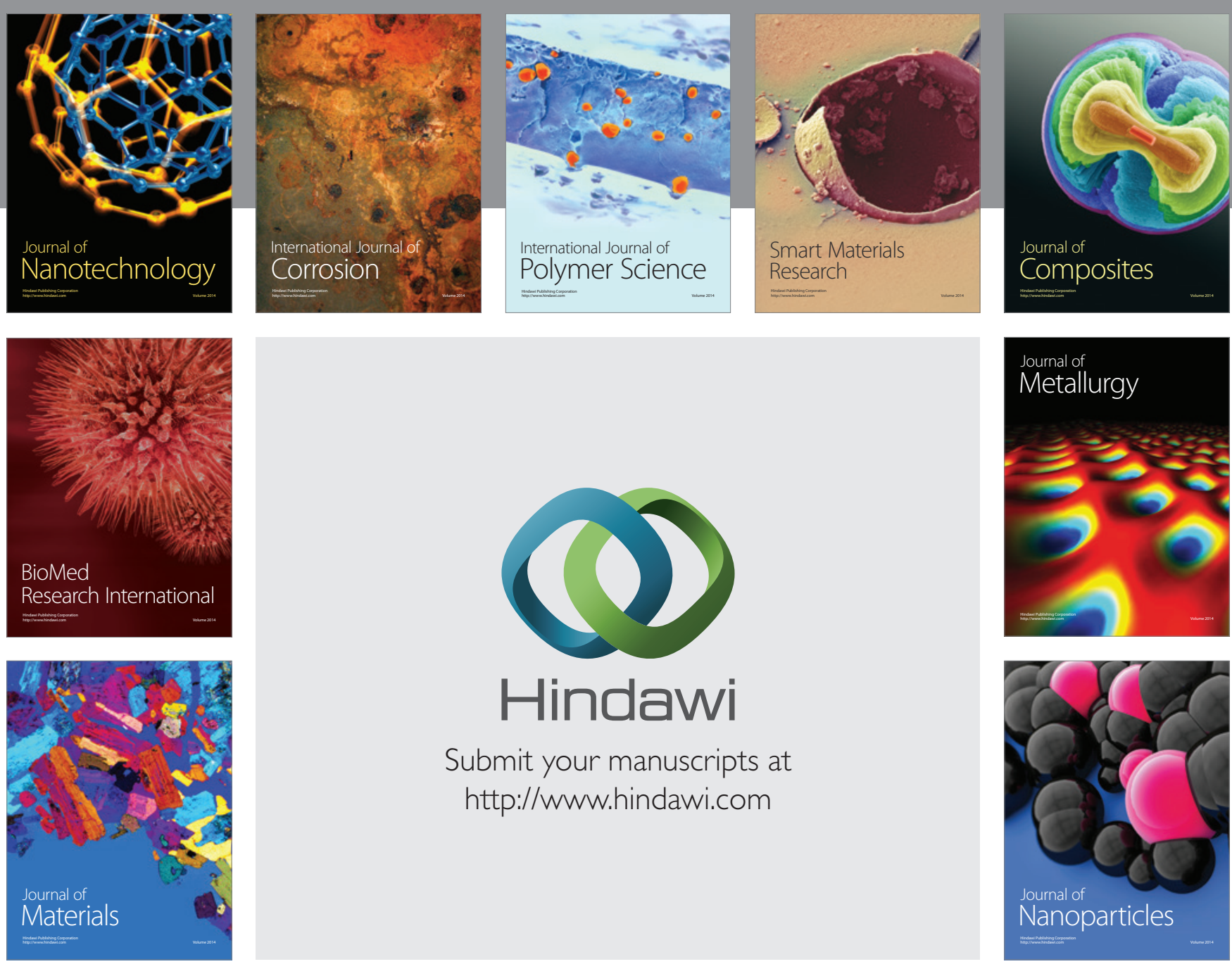

Submit your manuscripts at http://www.hindawi.com
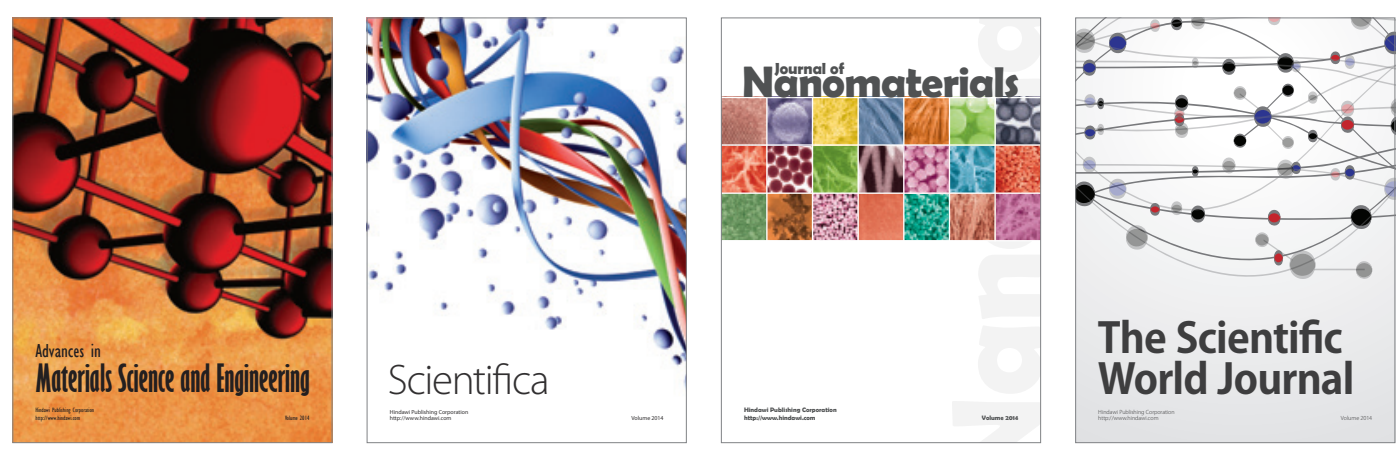

\section{The Scientific World Journal}
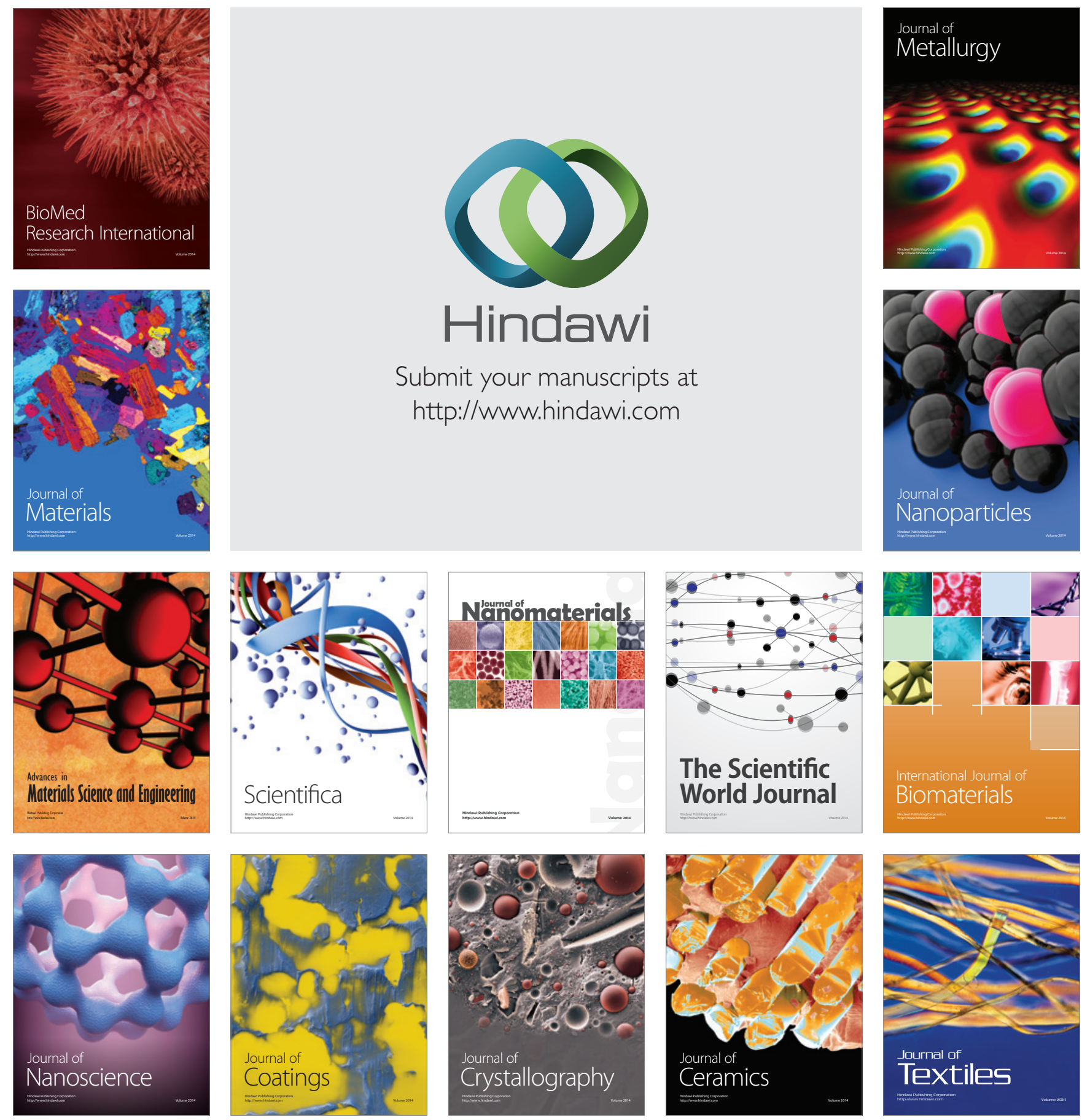